\title{
Pyrrolidine Dithiocarbamate Alleviated Anxiety in Diabetic Mice
}

\author{
G. CHU, C. LEI ${ }^{1}$, P. QIU, Y. HU AND X. MENG ${ }^{2}$
}

Department of Neurobiology, School of Basic Medicine, ${ }^{1}$ Department of Nephrology, Union Hospital, Tongji Medical College, China, ${ }^{2}$ Institute of Brain Research, Huazhong University of Science and Technology, Wuhan-430030, China

\author{
Chu, et al.: Antianxiety Potential of Pyrrolidine Dithiocarbamate
}

\begin{abstract}
Diabetes is often associated with psychological complications such as anxiety. The aim of this study was to evaluate the effects of pyrrolidine dithiocarbamate on anxiety of streptozotocin-induced diabetic mouse using the open field and the elevated plus maze tests. Confirmed diabetic mice $(>16.7 \mathrm{mM} / \mathrm{l}$ of blood glucose) were treated with pyrrolidine dithiocarbamate or $0.9 \%$ saline for $10 \mathrm{w}$. After pyrrolidine dithiocarbamate treatment, mice showed a higher percent of time retention and entries in open arms than the diabetic group in the elevated plus maze. However, there were no differences between total distance and average speed in both groups in the open field test. In conclusion, pyrrolidine dithiocarbamate treatment in diabetic mice exerted anxiolytic-like effects. The present study might be suggestive of a novel treatment approach to diabetic anxiety.
\end{abstract}

Key words: Diabetes, anxiety, pyrrolidine dithiocarbamate

Diabetes mellitus is the most common chronic endocrine metabolic disorder, which almost affect 366 million people in 2011, and predicted a rise to 552 million by $2030^{[1]}$. Diabetes is often associated with psychological complications such as anxiety ${ }^{[2,3]}$. It has been indicated that anxiety and anxiety related disorders are common in type 1 and 2 diabetic patients. Anxiety can be defined as an exaggerated emotional and dysfunctional state associated with hyper vigilance and increased behavioural responsiveness to fearful stimuli. Anxiety has been linked with a variety of behavioural variables, including poor disease management, higher health care costs, more days of missed work, which has severe impact on morbidity and mortality ${ }^{[4,5]}$. However, the underlying mechanisms of anxiety in diabetics still need to be elucidated.

New pathways linking inflammation and psychiatric diseases are discovered ${ }^{[6,7]}$. An emerging body of evidence suggests that inflammatory mechanisms may contribute to the development of anxiety disorders ${ }^{[8,9]}$. It has been shown that anxiety in patients and rodents exposed to acute stressors both show elevated serum levels of pro-inflammatory cytokines ${ }^{[10-12]}$. A number of studies have demonstrated increases in inflammatory markers such as tumour necrosis factor- $\alpha(\mathrm{TNF}-\alpha)$ and interleukins in anxiety related conditions including panic disorder and obsessive-compulsive disorder as well as anxiety related personality dimensions and diagnoses such as neuroticism and borderline personality disorder ${ }^{[13-15]}$. Therefore, inflammation is a recognized antecedent and coincident factor when examining the biology of anxiety.

Recent data have shown that phobic anxiety is associated with higher serum concentrations of adipokines and cytokines in women with diabetes ${ }^{[16]}$. Serum TNF- $\alpha$, a marker for inflammation, was found to increase by $1100 \%$ in diabetic rats ${ }^{[17]}$. Chronic diabetes activates microglia and significantly increases proinflammatory cytokine levels in the hippocampus ${ }^{[18]}$. Microglial cells are activated and pro-inflammatory cytokines are induced in the hippocampus of type 2 diabetic rats. All these data indicate that inflammation plays an important role in diabetics.

It has been shown that pyrrolidine dithiocarbamate (PDTC), an inhibitor of the activation of nuclear

This is an open access article distributed under terms of the Creative Commons Attribution-NonCommercial-ShareAlike 3.0 License, which allows others to remix, tweak, and build upon the work non-commercially, as long as the author is credited and the new creations are licensed under the identical terms.

Accepted 02 January 2017

Revised 30 October 2016

Received 20 June 2016

Indian J Pharm Sci 2017;79(1): 149-154 
factor $(\mathrm{NF}-\kappa \mathrm{B})$, produced a significant antianxiety like activity in stressed mice and reduced chronic normobaric hypoxia-induced anxiety like behaviour in rats $^{[19,20]}$. The characteristic long term upregulation of hippocampal NF- $\kappa B$ complex in post-traumatic stress disorder (PTSD) like behavioural stress response was normalized by high dose corticosterone and PDTC administered immediately after exposure ${ }^{[21]}$. However, whether PDTC affects anxiety in diabetics is still unknown. The aim of the present work was to determine the effects of PDTC on behavioural performance in anxiety tests of streptozotocin (STZ)-induced diabetic mice.

All experiments were performed according to the guidelines for use and care of laboratory animals and approved by the animal care and use committee (ACUC) of Tongji medical college of Huazhong university of science and technology. Mice were housed in groups of 4 animals per cage $(30 \times 19 \times 13 \mathrm{~cm})$ in a controlled environment with a $12 \mathrm{~h}$ light and $12 \mathrm{~h}$ dark cycle, average temperature of $22 \pm 2^{\circ}$, and $62 \pm 5 \%$ relative humidity with free access to chow and water (except during estimation of fasted blood glucose levels, where mice were fasted overnight). The animals were kept in our animal facility for at least $14 \mathrm{~d}$ before experiments.

Twenty-four mice were randomly divided into three groups: control mice, diabetic mice (DM) and diabetic mice with PDTC (PDM). To induce diabetes, mice from the diabetic mice and PDM groups received a single intraperitoneal injection of streptozotocin (STZ, 150 mg/kg; Enzo Life Sciences, Ann Arbor, MI, USA) freshly prepared in $5 \mathrm{M}$ sodium citrate, $\mathrm{pH}$ 4.5. Fasted blood glucose levels were monitored weekly using a glucometer. Blood was obtained via tail snip. Control mice were injected with sodium citrate. Only mice with stable glucose levels more than $16.7 \mathrm{mM} / 1$ (95\%) were considered as diabetic mice.

Two weeks after STZ injection, diabetes was confirmed again in all diabetic animals. Time zero (w 0 ) was considered the moment of the start of PDTC treatment. PDTC was freshly prepared in $0.9 \%$ saline with a concentration of $100 \mathrm{mg} / \mathrm{kg}$ and administrated by intraperitoneal injection at 10:00 am every other day for $10 \mathrm{w}$ to animals in the PDM group. In parallel, $0.9 \%$ saline was administrated to control mice and diabetic mice.

Ten weeks after PDTC treatment, behavioural testing was done during the light cycle. Mice were brought to the experimental room in their home cages $1 \mathrm{~h}$ before the behavioural experiments to allow acclimatization to the test environment. The behavioural room was kept very quiet to rule out noises, which might influence stress levels of animals. The experimental room was kept at a controlled temperature $(22 \pm 2)$. Mice were tested in the open field tests (OPT) and elevated plus maze (EPM) $24 \mathrm{~h}$ after the last dosing of vehicle or drug treatment so as to avoid the acute effect of the drugs. Only one test was performed each day to prevent the residual effects of the testing paradigms.

EPM was used to test anxiety like behaviours ${ }^{[22]}$. In brief, the apparatus consisted of a wooden maze with two enclosed arms $(35 \times 10 \times 40 \mathrm{~cm})$ and two open arms $(35 \times 10 \times 40 \mathrm{~cm})$ that extended from a central platform $(5 \times 5 \mathrm{~cm})$ to form a plus sign. The plus-maze apparatus was elevated to a height of $45 \mathrm{~cm}$ and placed inside a room free from noise and disturbances. Each mouse was placed on the central platform of the maze facing its head towards an open arm and left undistributed for $10 \mathrm{~min}$. The behavioural parameters, percentage open arm entries, percentage time spent in open arm and total arm entries, were recorded during a 5-min test period. Increased percentage of open arms activity referred to antianxiety effects, while a decrease in activity revealed elevated anxiety like behaviour in rodents. Entry into an arm was considered valid only when all four paws of the mouse were inside that $\operatorname{arm}^{[23,24]}$. The animal activities were recorded by a trained observer blind to the treatments. The apparatus was thoroughly cleaned with $70 \%$ ethanol after each trial to avoid the residual effects.

The OPT apparatus consists of a square Plexiglas cage $(35 \times 35 \times 40 \mathrm{~cm})$ with walls to minimize outside light and noise. The animals were individually placed in the centre of the OFT apparatus and were left to move freely during a 10 -min period.

The data are expressed as mean $\pm \mathrm{SEM}$ and results were analysed by one-way analysis of variance (ANOVA) followed by Dunnett's t-test. $\mathrm{P}<0.05$ were considered significant statistical analysis the data are expressed as mean \pm SEM and results. All values were expressed as mean \pm SEM. The results were statistically analysed by ANOVA followed by post-hoc Tukey's multiple comparison test. Results were considered significant with an alpha level of 0.05 and were considered to show a tendency between 0.05 and 0.1 .

It was found that plasma glucose levels were significantly elevated in diabetic mice $2 \mathrm{w}$ after STZ injection, as compared with their initial glucose levels. 
There was a significant decline in the body weights of STZ-treated mice as compared with their initial body weight. However, chronic PDTC treatment did not affect the body weight and plasma glucose levels, as compared to the diabetic group $(\mathrm{P}>0.05)$.

Mice were subjected to the EPM task $10 \mathrm{w}$ after PDTC treatment, as described above. As depicted in fig. 1. PDM group mice showed the increased tendency to explore open arms of the maze. Moreover, it was found that PDM group mice showed higher percentage of entries and spend less time in open arms as compared with DM group mice. In the open field test (fig. 2), there were no differences in travelled distance and average speed in 10 min among the three groups.

In the present study, we evaluated the effects of PDTC on behaviour performance of STZ-induced diabetic mice in anxiety tests. The diabetic mice showed high blood glucose levels. Our findings demonstrated that PDTC treatment changed behavioural profiles in mice with STZ-induced diabetes. It was observed that PDTC treatment produced anxiolytic like effects. These effects were shown in the EPM by a higher frequency of entries in open arms. Thus, the current finding clearly revealed that PDTC treatment can reverse anxiety-like behavioural abnormality as psychological consequences of diabetes.

It has been reported that the number of people affected with DM has been steadily increasing over the past few decades. Diabetes is often associated with psychological complications such as anxiety, which have severe impact on morbidity and mortality ${ }^{[25]}$. Therefore, anxiety may be a risk factor for diabetic complications $^{[26-28]}$. Streptozotocin-induced diabetes is among the most widely used preclinical models. STZ-induced diabetes has shown to elicit anxiety like behavioural deficits in rodents subjected to EPM, open field test, social interaction and zero maze tests ${ }^{[29,30]}$. Thus, researchers use STZ-induced diabetes to study diabetes-induced behavioural effects. Moreover, it is vital to find new targets and new compounds for treating mood disorders comorbid with diabetes.

Recently, it has been shown that NF- $\kappa \mathrm{B}$ is involved in CNS function ${ }^{[31-33]}$. NF- $\kappa \mathrm{B}$, originally discovered in $\mathrm{B}$ cells of the immune system, is widespread in neurons in adult brain, notably in the hippocampus, cerebral cortex and amygdala ${ }^{[34,35]}$. Recent studies have shown
A

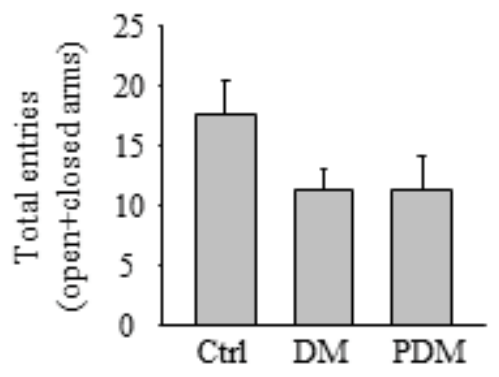

$\mathrm{C}$

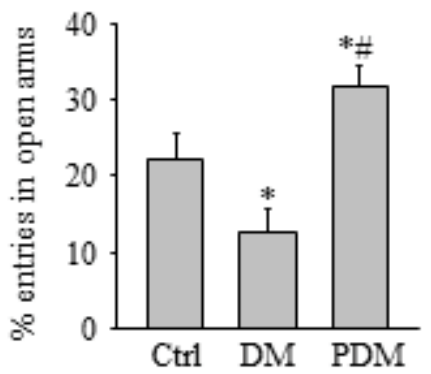

B

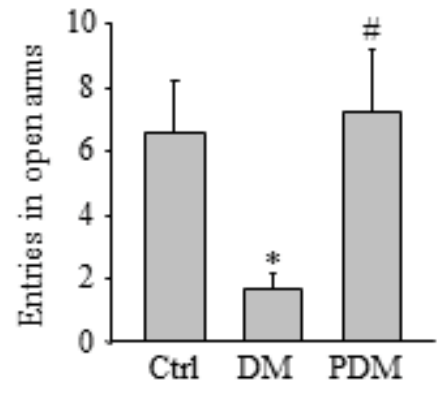

$\mathrm{D}$

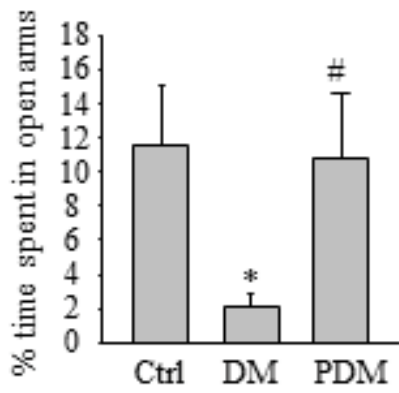

Fig. 1: Behavioural response of mice in the EPM after $10 \mathrm{w}$ treated with PDTC

A. Total entries of mice for $10 \mathrm{~min}$ in EPM; B. entries in open arms for $10 \mathrm{~min}$; C. percentage of entries in open arms; D. percentage of time spent in open arms. Ctrl: control; DM: diabetic mice; PDM: diabetic mice treated with PDTC. Panel bars displays means \pm SEM. $N=8, * P<0.05$ vs. control; \# $\mathrm{P}<0.05$ vs. DM group 
A

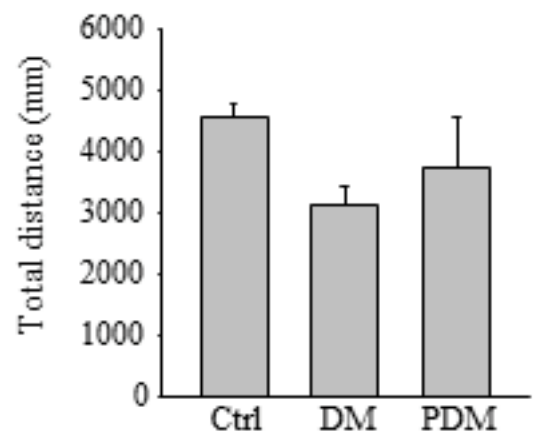

B

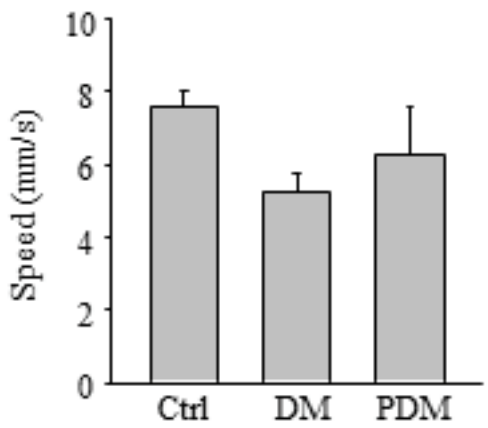

Fig. 2: Behavioral response of mice in the OFT

A. Total distance for $10 \mathrm{~min}$ in OFT; B. Average speed of mice in OFT. Panel bars displays means \pm SEM, $\mathbf{n}=8$

that NF- $\mathrm{kB}$ plays an important role in physiological and pathological functions in neurons of $\mathrm{CNS}^{[36,37]}$. It has been reported that NF- $\mathrm{KB}$ is involved in chronic neurodegenerative diseases such as Alzheimer's disease and Parkinson's disease ${ }^{[38,39]}$. NF- $\kappa B$ also plays an important role in neurite outgrowth, synaptogenesis and synaptic plasticity ${ }^{[40]}$. The identified NF- $\mathrm{KB}$ complexes were primarily $\mathrm{p} 50 / \mathrm{p} 65$ heterodimers and also p50/ p50 homodimers in CNS. It has been shown that the $\mathrm{p} 50^{-/-}$mice showed significantly less defecation, more rearing, and more time spent in the centre compartment relative to wild type control mice $\mathrm{n}$ an open field. The mutant mice also spent more time investigating a novel object placed in the open field. On the EPM, $\mathrm{p} 50^{-/-}$mice spent more time on the open arms and had increased numbers of open arm entries relative to wild type. Therefore, NF- $\mathrm{BB}$ p50-deficient mice show reduced anxiety-like behaviours ${ }^{[41]}$. It has been reported that the expression and nuclear translocation of NF- $\kappa \mathrm{B}$ p 65 was elevated in the hippocampus and frontal cortex of diabetic mice ${ }^{[42,43]}$. Inhibition the expression of NF$\kappa \mathrm{B}$ ameliorated memory deficits in diabetic mice ${ }^{[44]}$. However, whether NF- $\mathrm{BB}$ is involved in anxiety-like behaviour in diabetes is still unknown. In the present study, we used PDTC, an NF- $\kappa$ B inhibitor, to explore $\mathrm{NF}-\kappa \mathrm{B}$ mediated diabetic anxiety. It was found that diabetic mice after STZ-induced diabetic condition for $12 \mathrm{w}$ exhibited a significant decrease in the percentage of open arm entries, which accorded with previous reports ${ }^{[29,45]}$. It was interesting that PDTC treatment for $10 \mathrm{w}$ after STZ injection for $2 \mathrm{w}$ reversed anxiety like behaviour induced by diabetic condition in mice as detected by EPM.

In conclusion, the present study utilized EPM to explore whether PDTC affected the anxiety like behaviours in STZ-induced diabetic mice. It was found that diabetic mice showed a significant increase of anxiety like behaviours, which could be reversed by long term PDTC treatment. The present study gave rise to opportunities for newer therapies that could be developed for anxiety associated with diabetes.

\section{Acknowledgments:}

This work was supported by grants from the National Natural Science Foundation of China (81671066,81471490 and 81170600).

\section{Conflict of interest:}

The authors declare no conflicts of interest.

\section{Financial support and sponsorship:}

Nil.

\section{REFERENCES}

1. Alam U, Asghar O, Azmi S, Malik RA. General aspects of diabetes mellitus. Handb Clin Neurol 2014;126:211-22.

2. Abazarian E, Baboli MT, Ghashghaei FE. The effect of problem solving and decision making skills on tendency to depression and anxiety in patients with type 2 diabetes. Adv Biomed Res 2015;4:112.

3. Strandberg RB, Graue M, Wentzel-Larsen T, Peyrot M, Rokne B. Relationships of diabetes-specific emotional distress, depression, anxiety, and overall well-being with HbA1c in adult persons with type 1 diabetes. J Psychosom Res 2014;77:174-9.

4. Lynch CP, Gebregziabher M, Zhao Y, Hunt KJ, Egede LE. Impact of medical and psychiatric multi-morbidity on mortality in diabetes: emerging evidence. BMC Endocr Disord 2014;14:68.

5. Al Hayek AA, Robert AA, Al Saeed A, Alzaid AA, Al Sabaan FS. Factors Associated with Health-Related Quality of Life among Saudi Patients with Type 2 Diabetes Mellitus: A Cross-Sectional Survey. Diabetes Metab J 2014;38:220-9.

6. Moulton CD, Pickup JC, Ismail K. The link between depression and diabetes: the search for shared mechanisms. Lancet Diabetes Endocrinol 2015;3:461-71.

7. Rook GA, Raison CL, Lowry CA. Microbiota, immunoregulatory old friends and psychiatric disorders. Adv Exp Med Biol 2014;817:319-56.

8. Moons WG, Shields GS. Anxiety, not anger, induces 
inflammatory activity: An avoidance/approach model of immune system activation. Emotion 2015;15:463-76.

9. Abbott R, Whear R, Nikolaou V, Bethel A, Coon JT, Stein K, et al. Tumour necrosis factor- $\alpha$ inhibitor therapy in chronic physical illness: A systematic review and meta-analysis of the effect on depression and anxiety. J Psychosom Res 2015;79:175-84.

10. Furtado M, Katzman MA. Neuroinflammatory pathways in anxiety, posttraumatic stress, and obsessive compulsive disorders. Psychiatry Res 2015;229:37-48.

11. Sulakhiya K, Kumar P, Gurjar SS, Barua CC, Hazarika NK. Beneficial effect of honokiol on lipopolysaccharide induced anxiety like behavior and liver damage in mice. Pharmacol Biochem Behav 2015;132:79-87.

12. Pascual M, Balino P, Aragon CM, Guerri C. Cytokines and chemokines as biomarkers of ethanol-induced neuroinflammation and anxiety-related behavior: role of TLR4 and TLR2. Neuropharmacology 2015;89:352-59.

13. Holmgren S, Hjorth E, Schultzberg M, Larksater M, Frenkel $\mathrm{D}$, Tysen-Backstrom AC, et al. Neuropsychiatric symptoms in dementia-a role for neuroinflammation? Brain Res Bull 2014;108:88-93.

14. Glaus J, Vandeleur CL, von Kanel R, Lasserre AM, Strippoli MP, Gholam-Rezaee M, et al. Associations between mood, anxiety or substance use disorders and inflammatory markers after adjustment for multiple covariates in a population-based study. J Psychiatr Res 2014;58:36-45.

15. Sutin AR, Terracciano A, Deiana B, Naitza S, Ferrucci L, Uda $\mathrm{M}$, et al. High neuroticism and low conscientiousness are associated with interleukin-6. Psychol Med 2010;40:1485-93.

16. Andre C, Dinel AL, Ferreira G, Laye S, Castanon N. Dietinduced obesity progressively alters cognition, anxiety-like behavior and lipopolysaccharide-induced depressive-like behavior: focus on brain indoleamine 2,3-dioxygenase activation. Brain Behav Immun 2014;41:10-21.

17. Kuhad A, Chopra K. Curcumin attenuates diabetic encephalopathy in rats: behavioral and biochemical evidences. Eur J Pharmacol 2007;576:34-42.

18. Hwang IK, Choi JH, Nam SM, Park OK, Yoo DY, Kim W, et al. Activation of microglia and induction of pro-inflammatory cytokines in the hippocampus of type 2 diabetic rats. Neurol Res 2014;36:824-32.

19. Sharma V, Gilhotra R, Dhingra D, Gilhotra N. Possible underlying influence of p38MAPK and NF- $\kappa B$ in the diminished anti-anxiety effect of diazepam in stressed mice. J Pharmacol Sci 2011;116:257-63.

20. Fan J, Fan X, Li Y, Guo J, Xia D, Ding L, et al. Blunted inflammation mediated by NF- $\kappa$ B activation in hippocampus alleviates chronic normobaric hypoxia-induced anxiety-like behavior in rats. Brain Res Bull 2016;122:54-61.

21. Cohen H, Kozlovsky N, Matar MA, Zohar J, Kaplan Z. The characteristic long-term upregulation of hippocampal NF- $\kappa \mathrm{B}$ complex in PTSD-like behavioral stress response is normalized by high-dose corticosterone and pyrrolidine dithiocarbamate administered immediately after exposure. Neuropsychopharmacology 2011;36:2286-302.

22. Lister RG. The use of a plus-maze to measure anxiety in the mouse. Psychopharmacology 1987;92:180-5.

23. Klodzinska A, Tatarczynska E, Stachowicz K, ChojnackaWojcik E. The anxiolytic-like activity of AIDA (1-aminoindan1,5-dicarboxylic acid), an mGLu 1 receptor antagonist. J Physiol Pharmacol 2004;55:113-26.
24. Biala G, Kruk M. Calcium channel antagonists suppress cross-tolerance to the anxiogenic effects of D-amphetamine and nicotine in the mouse elevated plus maze test. Prog Neuropsychopharmacol Biol Psychiatry 2008;32:54-61.

25. Dismuke CE, Hernandez-Tejada MA, Egede LE. Relationship of serious psychological distress to quality of life in adults with diabetes. Int J Psychiatry Med 2014;48:135-46.

26. Ducat L, Rubenstein A, Philipson LH, Anderson BJ. A review of the mental health issues of diabetes conference. Diabetes Care 2015;38:333-8.

27. Farvid MS, Qi L, Hu FB, Kawachi I, Okereke OI, Kubzansky LD, et al. Phobic anxiety symptom scores and incidence of type 2 diabetes in US men and women. Brain Behav Immun 2014;36:176-82.

28. Svenningsson I, Bjorkelund C, Marklund B, Gedda B. Anxiety and depression in obese and normal-weight individuals with diabetes type 2: a gender perspective. Scand J Caring Sci 2012;26:349-54.

29. Gupta D, Radhakrishnan M, Kurhe Y. Insulin reverses anxietylike behavior evoked by streptozotocin-induced diabetes in mice. Metab Brain Dis 2014;29:737-46.

30. Damian JP, Acosta V, Da Cuna M, Ramirez I, Oddone $\mathrm{N}$, Zambrana A, et al. Effect of resveratrol on behavioral performance of streptozotocin-induced diabetic mice in anxiety tests. Exp Anim 2014;63:277-87.

31. Haenold R, Weih F, Herrmann KH, Schmidt KF, Krempler K, Engelmann $\mathrm{C}$, et al. NF- $\mathrm{B}$ controls axonal regeneration and degeneration through cell-specific balance of RelA and p50 in the adult CNS. J Cell Sci 2014;127:3052-65.

32. Maqbool A, Lattke M, Wirth T, Baumann B. Sustained, neuron-specific IKK/NF- $\mathrm{B}$ activation generates a selective neuroinflammatory response promoting local neurodegeneration with aging. Mol Neurodegener 2013;8:40.

33. Koo JW, Russo SJ, Ferguson D, Nestler EJ, Duman RS. Nuclear factor- $\kappa \mathrm{B}$ is a critical mediator of stress-impaired neurogenesis and depressive behavior. Proc Natl Acad Sci USA 2010;107:2669-74.

34. Terai K, Matsuo A, McGeer PL. Enhancement of immunoreactivity for NF- $\mathrm{BB}$ in the hippocampal formation and cerebral cortex of Alzheimer's disease. Brain Res 1996;735:159-68.

35. Clemens JA, Stephenson DT, Smalstig EB, Dixon EP, Little $\mathrm{SP}$. Global ischemia activates nuclear factor- $\kappa \mathrm{B}$ in forebrain neurons of rats. Stroke 1997;28:1073-80.

36. He JJ, Li S, Shu HF, Yu SX, Liu SY, Yin Q, et al. The interleukin 17 system in cortical lesions in focal cortical dysplasias. J Neuropathol Exp Neurol 2013;72:152-63.

37. Imielski Y, Schwamborn JC, Luningschror P, Heimann P, Holzberg $\mathrm{M}$, Werner $\mathrm{H}$, et al. Regrowing the adult brain: $\mathrm{NF}-\kappa \mathrm{B}$ controls functional circuit formation and tissue homeostasis in the dentate gyrus. PLoS One 2012;7.

38. Ghosh A, Roy A, Matras J, Brahmachari S, Gendelman HE, Pahan K. Simvastatin inhibits the activation of p21ras and prevents the loss of dopaminergic neurons in a mouse model of Parkinson's disease. J Neurosci 2009;29:13543-56.

39. Yoshiyama Y, Arai K, Hattori T. Enhanced expression of $\mathrm{I}-\kappa \mathrm{B}$ with neurofibrillary pathology in Alzheimer's disease. Neuroreport 2001;12:2641-45.

40. Boersma MC, Dresselhaus EC, De Biase LM, Mihalas AB, Bergles DE, Meffert MK. A requirement for nuclear factor- $\kappa B$ 
in developmental and plasticity-associated synaptogenesis. J Neurosci 2011;31:5414-25.

41. Kassed CA, Herkenham M. NF- $\mathrm{B}$ p50-deficient mice show reduced anxiety-like behaviors in tests of exploratory drive and anxiety. Behav Brain Res 2004;154:577-84.

42. Du GT, Hu M, Mei ZL, Wang C, Liu GJ, Long Y, et al. Telmisartan treatment ameliorates memory deficits in streptozotocin-induced diabetic mice via attenuating cerebral amyloidosis. J Pharmacol Sci 2014;124:418-26.

43. Zhou X, Zhang F, Hu X, Chen J, Wen X, Sun Y, et al.
Inhibition of inflammation by astaxanthin alleviates cognition deficits in diabetic mice. Physiol Behav 2015;151:412-20.

44. Jia D, Heng LJ, Yang RH, Gao GD. Fish oil improves learning impairments of diabetic rats by blocking PI3K/AKT/nuclear factor- $\kappa \mathrm{B}$-mediated inflammatory pathways. Neuroscience 2014;258:228-37.

45. Aksu I, Ates M, Baykara B, Kiray M, Sisman AR, Buyuk E, et al. Anxiety correlates to decreased blood and prefrontal cortex IGF-1 levels in streptozotocin induced diabetes. Neurosci Lett 2012;531:176-81. 